ASI

1912 


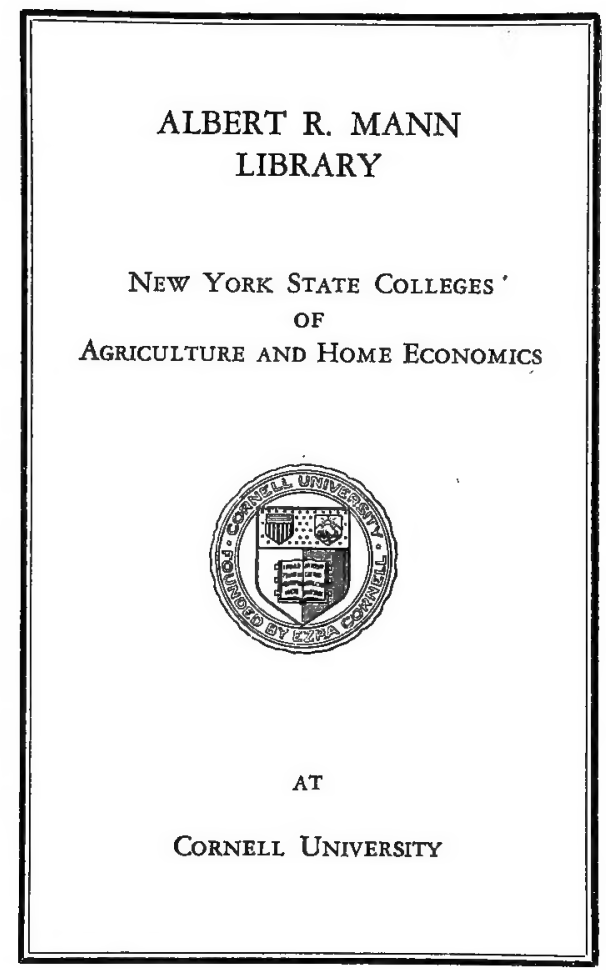




\section{Cornell University Library}

SB 353.A51 1912

Mushroom culture and pure culture spawn.

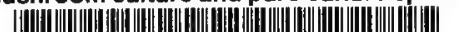

31924003397134 


\section{Suggestions to Growers}

\section{(PRESERVE FOR REFERENCE)}

A simple method for the preparation of a small bed for amateurs and beginners is described on page 25 .

For varieties of mushrooms, see page 23 and the illustrations.

Retail prices of spawn are given on page 22 .

Before ordering from your dealer do not fail to read chapter 18, page 21. The practice of ordering by the pound should be discontinued. Order by the brick and enclose remittance with your order. Specify the kind of brick wanted, whether "Standard" or "Direct." See page 23.

For lawns and pastures, inquire from your dealer for special stock. See page 16.

Commercial growers who are supplying the market will find it to their advantage to enclose in each basket, printed recipes for cooking and preserving mushrooms. It is surprising how many people abstain from buying mushrooms because they do not know and cannot learn how to prepare them. Valuable recipes will be found on pages 26 to 30 . bed.

One brick of Lambert's Pure Culture Spawn will plant 8 square feet of

The whole secret in raising mushrooms lies in the control of atmospheric conditions, temperature and moisture, and in the proper preparation of the compost. (See pages 6 to 12.)

If you desire our further publications on the subject of Mushroom Culture, please advise the American Spawn Co., St. Paul, Minn. See page 32.

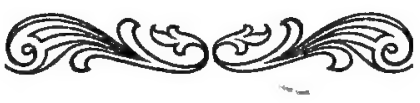


Publication No. 3

\section{Mushroom Culture and \\ Pure Culture Spawn}

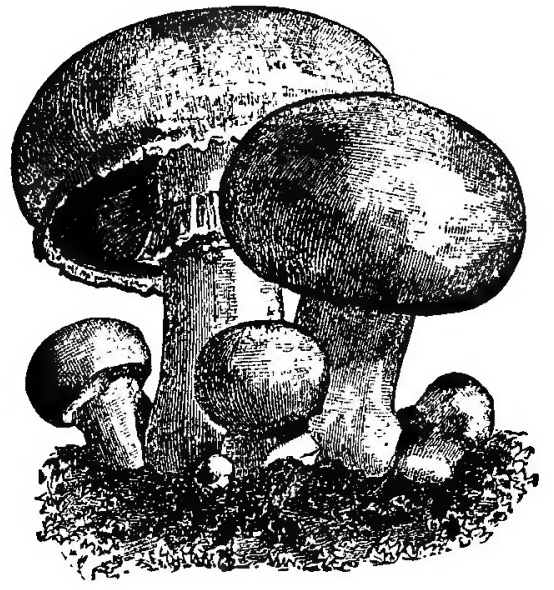

Seventh Edition

\section{PRICE 35 CENTS}

BY 


\section{$3 \%$. OLIZ TABLE OF CONTENTS}

Page

Preface

1 The cultivated mushroom

2 Market conditions

3 General considerations

4 Temperature and moisture

5 Caves, cellars, and houses

6 Preparation of the compost............. 9

7 Installation of beds

8 Spawning and casing the beds

9 Watering $\ldots$

10 Picking and preparing for market

11 Old beds . ......... 16

12 Open air culture

13 Mushroom enemies...................... 17

14 Mushroom spawn .................. 19

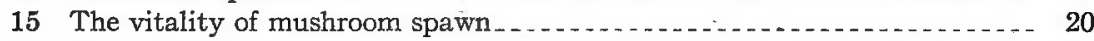

16 Storage of spawn.......... 20

17 Pure culture spawn

18 How and when to order spawn

19 Price of pure culture spawn

20 Pure culture varieties....... 23

21 Trade mark

22 Special hints on cultivation

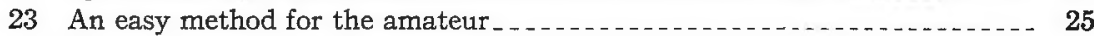

24 How to cook mushrooms . . . . . . . . . . . . . . . . . . . 26

25 How to preserve mushrooms

26 Poisonous and edible mushrooms . . . . .

27 Our publications $\ldots \ldots \ldots \ldots \ldots \ldots \ldots$

\section{ILLUSTRATIONS}

Cat. No. 7, Brown

Cat. No. 8, Cream White........... " 9

Cat. No. 9, White

Cat. No. 10, Light Brown

Cat. No. 11, Cream.... u " 20

Cat. No. 12, Cream

A Cluster of Mushrooms

Pure Culture Spawn 


\section{PREFACE}

\section{To the Mushroom Growers:}

Numerous inquiries for reliable information on the best method of growing mushrooms are constantly received, and we have taken this method of answering them collectively. While many failures in mushroom growing are attributable to poor spawn, it is also true that good spawn will give poor or negative results where the essential principles of cultivation have been disregarded.

The manufacturer of a high grade of mushroom spawn is equally interested with the grower in acquainting him with the latest developments of science in mushroom growing. He may thus be instrumental in removing many causes of failure which the uninformed grower would otherwise charge to the spawn.

The discovery of the "pure culture" method of making spawn and the resulting segregation of the varieties carries with it the consequent necessity for careful selection of the varieties to be planted, under the varying conditions surrounding different growers, with a view of avoiding serious mistakes and obtaining maximum results.

Notwithstanding some extravagant statements which have recently found their way into print, it is certain that the millennium has not yet been reached in mushroom culture or in spawn making. However, the discovery of pure culture spawn has marked a new era in the history of this industry; important and positive results have been obtained, phenomenal crops have been raised under proper conditions; but maximum results are only possible by the application of scientific principles and the adoption of the most approved methods of cultivation.

We will, therefore, make known from time to time, in subsequent publications. the latest developments in mushroom culture, based upon practical experience, provided we are furnished with the name and address of the parties desiring to receive the same.

\section{AMERICAN SPAWN COMPANY,}

St. Paul, Minn.

NOTE-The first sixteen chapters of this publication are based upon extracts from the reports of Dr. B. M. Duggar, of the Department of Argiculture. 


\section{The Cultivated Mushroom}

In the United States the term "mushroom" refers commercially to but a single species (Agaricus campestris). of the fleshy fungi, a plant common throughout most of the temperate regions of the world, and one everywhere recognized as edible. From the time of Pliny, and perhaps much earlier, this plant has been sought as an article of diet, and it has been cultivated for many centuries. In the vicinity of Paris it has certainly been cultivated in some quantity since the sixteenth century; and, in paintings of market scenes by old masters of the seventeenth century, a basket of mushrooms frequently finds a place in the composition, thus showing that at that time the sale of mushrooms was generally recognized in a commercial way.

The fully expanded plant, or mature mushroom (sporophore), of Agaricus campestris is well known to every one. It consists of a centrally placed stock or stipe of from 2 to 6 inches in height, usually not more than one inch in diameter, and on the end of this stipe there is borne an umbrella-shaped or cap-shaped portion known as the cap or pileus. The diameter and thickness of this pileus vary in different races or varieties of the cultivated form, and also with the conditions of the environment under which it is produced. The general color of the plant varies in the different varieties from an almost pure white, or cream, to the forms which are deep brown, at least with reference to the upper surface of the cap. The stem is usually cream or white, and bears on its upper extremity near the cap a ring known as the annulus, which annulus forms a covering and a protecting layer for the delicate under surface of the cap, to the edges of which it, was attacked previous to the rapid expansion and maturity of the latter. The under surface of the cap is provided with leaflike or gill-like projections, reaching for the most part from the stem to the periphery of the cap. These are termed gills, or "lamellae." They are constantly pink in color in the white or cream-colored species up to the time of (and sometimes even a day after) the separation of the ring from the cap. Subsequently these gills turn brown and even a deep brownish black. In the brown variety the gills are at first grayish brown but they also become almost black with age.

\section{Market Conditions}

The successful cultivation of mushrooms in America has not been so general as in most of the European countries. It is in France and England that the mushroom industry has been best developed. France is, properly speaking, the home of the present mushroom industry. Unusual interest has been shown in the United States in the growth of mushrooms within the past few. 
years, and it is to be hoped and expected that within the next ten years the industry will develop to the fullest limit of the market demands. The latter will, of course, be stimulated and developed by the increasing popular appreciation of this product. In some cities and towns there is already a good market demand for mushrooms, while in others they may be sold only directly to special customers. This should be borne in mind by prospective growers.

In the vicinity of Paris the mushroom industry has been remarkably developed during the past eight or ten years. The total product sold through the central market of Paris in 1898 was nearly $4,000,000$ pounds; the quantity for 1900 is given as approximately $8,500,000$ pounds, and for 1901 nearly $10,000,000$ pounds.

These figures show most convincingly the present status of the mushroom industry in France. It may be safely assumed that more than one-third of this quantity is consumed in a fresh state in and about the city. The growth of the canning industry during this period has also been remarkable. In 1898 about $1,800,000$ pounds were preserved, while in 1901 the canned product amounted to nearly $6,200,000$ pounds. During 1901 the approximate monthly production of mushrooms ranged from 651,000 pounds to 985,000 pounds, from which it is evident that these caves yield heavily throughout the year. In some instances growers are able to get a crop every four or five months.

It is extremely difficult to estimate the quantity of mushrooms grown in the United States. It is certain, however, that the production has increased very greatly, and particularly within the last four or five years. In the vicinity of several of our larger cities there are today individual growers who produce more than the total commercial output in the neighborhood of those cities ten years ago.

There is now a very good open market for fresh mushrooms in a few of the larger cities, although many large growers continue to sell entirely by contract or by special orders to hotels and restaurants. With such an enormous comparative consumption of the canned product, there is every reason to believe that fresh mushrooms can be sold in much greater quantity as soon as this product becomes a certain factor in the market.

\section{General Considerations}

In the United States fresh mushrooms have only recently been of any importance commercially, although florists and gardeners of English and French training have long been successful growers on a small scale. Nevertheless, during the past decade or so, the record of failures has been most conspicuous, and it is certain that of the many who attempted this work, only a few, relatively, were uniformly successful. 
The conditions under which mushrooms may be successfully grown are limited, and intelligent attention is therefore essential. It must be said, moreover, that the majority of failures may be directly traced to erroneous ideas as to the cultural requisites, or to a reckless disregard of conditions. The essential conditions, will be subsequently defined in detail, but it may be stated here that failures are usually due to one or more of the following causes: (1) Poor spawn; (2) very poor manure; 3) unfavorable temperature; and (4) heavy watering during the early stages of growth.

Under suitable conditions mushrooms may be grown with assurance of success. Ordinarily they are grown only where the conditions may be controlled, and success should therefore be invariable.

\section{Temperature and Moisture}

Mushrooms may be grown in any place where the conditions of temperature and moisture are favorable. A shed, cellar, cave, or vacant space in a greenhouse may be utilized to advantage for this purpose. The most essential factor, perhaps, is that of temperature. The proper temperature ranges from $53 \mathrm{deg}$. to $60 \mathrm{deg}, \mathrm{F}$., with the best from 55 to $58 \mathrm{deg}$. F. It is unsafe to attempt to grow mushrooms on a commercial basis, according to our present knowledge of the subject, at a temperature much less than 50 deg. or greater than $63 \mathrm{deg} . \mathrm{F}$. Any severe changes of temperature retard growth, or else act injuriously, and many changes of temperature would entirely destroy the profits of the mushroom crop. From this it is evident that in many places mushrooms may not be grown as a summer crop. With artificial heat they may be grown almost anywhere throughout the winter. Moreover, it is very probable that in this country open-air culture must be limited to a few sections, and restricted, commercially at least, to a single season.

It is very probable that the exact temperature which may be considered an optimum will vary somewhat in different sections of the country. It will be noted later in detail that the temperature factor acts not so directly upon the growth of the spawn or the production of mushrooms as indirectly to render some other conditions of the environment injurious. - It is best to consider that in practice the optimum temperature for mushroom growing varies from $53 \mathrm{deg}$. to $58 \mathrm{deg}$. F.

It was soon definitely ascertained that the conditions of pure culture growth are essentially different from those attending the growth of mushroom spawn in the bed. This was perhaps best indicated by comparing spawn grown in pots at $85 \mathrm{deg}$. F. under impure conditions with similar spawn grown at 50 deg. $F$. At the former temperature, even though the conditions of moisture were properly maintained, there was little or no growth. Foreign fungi, molds, and bacteria, as well as insects, were, however, abundant. 
At the lower temperature there was little or no evident appearance of other fungi, molds, or insects; yet the mushroom spawn grows slowly and continuously so long as other conditions are maintained. From numerous experiments of this nature, it is apparent that the temperature relation is one which is governed by the competition to which the mushroom spawn is subject in the bed. This is, of course, wholly in accord with the results obtained from the study of the relative growth made by mushroom spawn in fresh and composted manure.

The statement previously made, therefore, that the optimum temperature may vary slightly in different localities is true on account of the fact that the mites, insects, and other animal pests of mushroom growing may vary considerably in different localities, or under different conditions, even though there may not be a great variation, perhaps, in the bacterial and fungus flora of the compost upon which the mushrooms are grown. Certain insects, for example, are more abundant in a moist climate, but if special precautions can be taken to eliminate all such pests, the growth problem is confined to the interrelation existing between the mushroom spawn and the microscopic flora of the compost. Mushrooms grown in the open will probably show greater variation with reference to the temperature factor than those grown in caves or cellars.

The direct effect of a temperature above the optimum upon the aporophores is manifest through lengthening of the stipes and rapid expansion of the caps, ordinarily accompanied by toughness and decreased size. In other words, the lower grade market product is produced at the higher temperature.

The moisture factor is also one of importance. It is undesirable that the place in which mushrooms are grown should be very damp, or dripping with water. Nevertheless, a fairly moist condition of the atmosphere should be maintained throughout the growing and productive period. There should be a gradual but slight evaporation from the surface of the beds and sufficient ventilation to insure this, is believed to be essential. It is certain that in poorly ventilated caves mushrooms do not succeed. On the other hand, in a dry atmosphere, or exposed to drying winds, mushroom beds soon cease to bear, while such sporophores as are developing may have their caps cracked or torn. 


\section{Caves, Cellars and Houses}

Cellars, caves, and abandoned mines, or specially constructed houses are used for growing mushrooms, because in such places only can the conditions of temperature and moisture be best regulated. Cold is less injurious to mushroom beds than heat. The

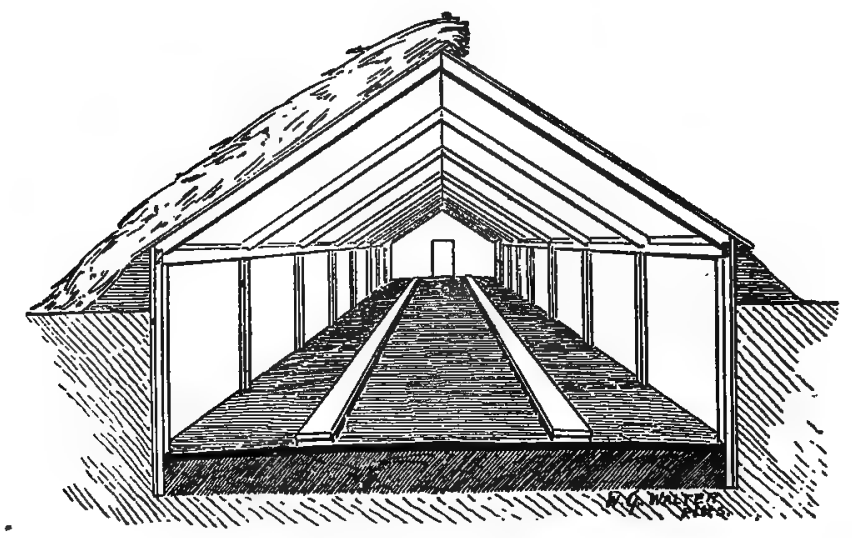

former renders the bed for a time unproductive; but the latter stimulates the spawn to too rapid growth, which is usually followed by the production of unsalable mushrooms, or by the eventual death of the spawn, supposedly by damping off.

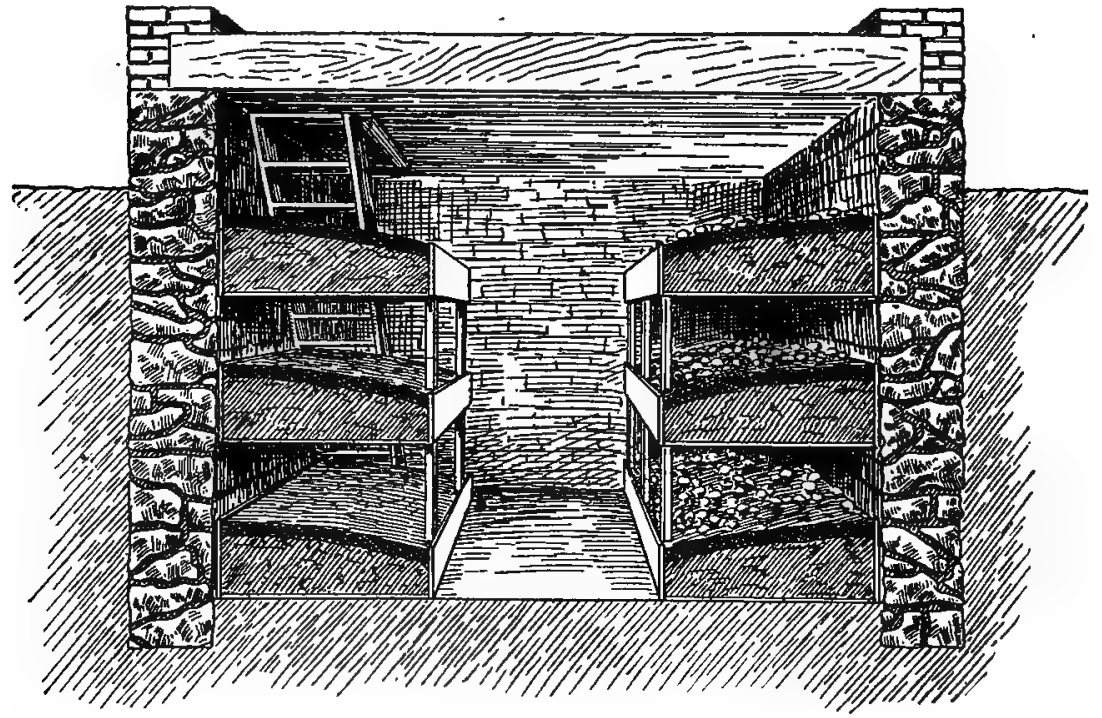




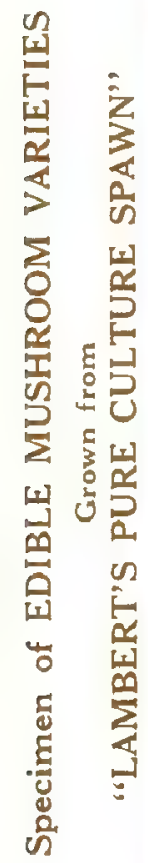

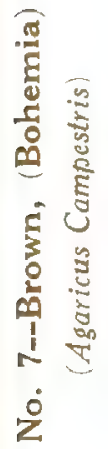




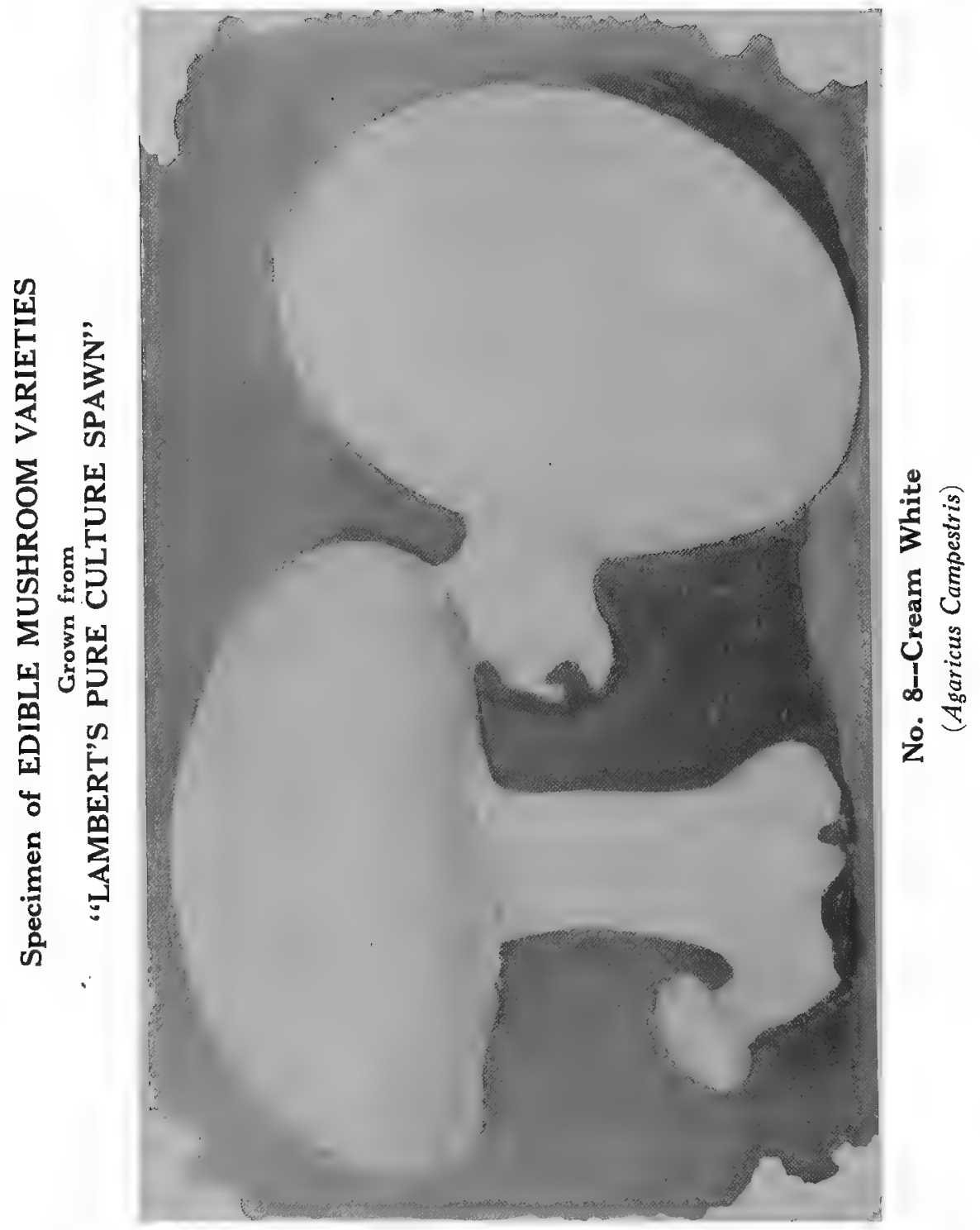


Mushrooms may often be grown in a very simply constructed shed or unused barn which will provide against any sudden changes of the temperature, and when it is possible to employ artificial heat the season for mushroom production in such structures may be greatly extended. Cellars are very commonly used in producing mushrooms for family use. Natural or artificial caves are of the first importance, however, for commercial work, since the situation of these below the surface will best insure a temperature throughout almost the entire year more or less close to that which is desired. In selecting caves or cellars, one should guard against the possibility of flooding or of too much seepage water during a rainy season. Perhaps the least satisfactory situation among those mentioned is the greenhouse. Under ordinary circumstances it heats up too readily during the days of warm sunshine and, unless special precautions are taken, it is not to be generally recommended for amateurs. Nevertheless, during the fall and winter it is possible to grow mushrooms under the benches or in any other unused space with but very little outlay of money or labor. Cold frames may also be used to good advantage during the autamn or spring. The natural caves of this country and abandoned coal mines in some sections should be further investigated with relation to their adaptability for the commercial production of mushrooms. A thorough study should also be made of open air conditions.
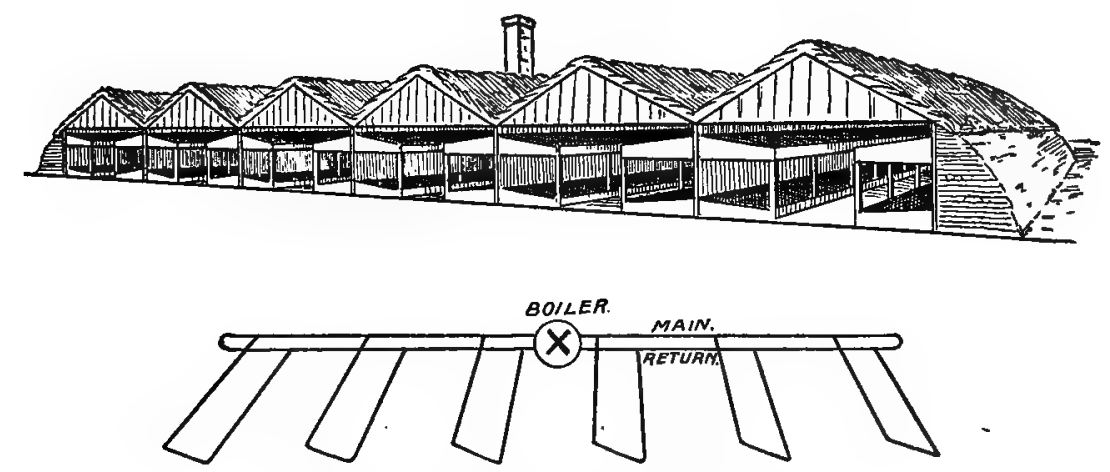

PEPSPECTIVE OF HEATING PIPES.

In the construction of special mushroom houses any one of a variety of plans may be followed, and the selection of the style will depend, of course, upon its cheapness and efficiency in the particular locality.

\section{Preparation of the Compost}

It is not to be understood that there is one and only one method of preparing compost for mushroom growing. Nor is it always 
necessary that the compost shall be in one particular stage of fermentation or decay. In fact, every change of condition elsewhere may necessitate a similar change in the amount of fermentation which may be most desirable. At the outset it should be understood that it is not the "fermentation" that is absolutely essential. The "fermentation" is of itself a minor matter.

The rapid oxidation action of bacteria, and perhaps of independent ferments, upon manure causes a considerable rise of temperature. At the higher temperatures (which may be maintained as long as there are present rapidly oxidizable food products) bacterial action is vigorous, and is unquestionably injurious to mycelial development. Wholly aside from the rise of temperature accompanying their activities, bacteria are otherwise injurious. In fact, manure which is put to test in a small test tube shows little or no rise of temperature above that of the place in which it is incubated. Nevertheless, the mycelium of the mushroom will not grow under such conditions. Rapid bacterial action is therefore prejudicial. Under those conditions where bacterial action is not rapid, fresh manure might be used to advantage; in other words, if the beds are so constructed that the manure ferments very gradually, without either excessive bacterial action or rise of temperature, then spawning might be made in fresh manure.

The old belief that rotten manure does not have the necessary strength-that is, does not produce so vigorous a mushroom growth as that which has been less transformed by bacterial action-has been confirmed by practical experiments. This loss of effectiveness is probably due, in part, to a change in texture or to other physical changes. In well-rotted manure there is ample food material to support a. very good growth of mycelium in pure cultures. This has been chemically proved by sterilizing such manure and growing mushroom spawn upon it in pure culture. Nevertheless, beds prepared with well-fermented manure and left for some time before spawning do not yield so well. It is believed that here the physical condition has much to do with the result.

The latter does not by any means invalidate the following practice, which has commended itself to some very successful growers. The manure is piled in very large compost heaps, where it is kept moist and is turned only once or twice. It ferments very slowly. Then it is carted into the cave or mushroom house, long before it could be considered in proper condition to be spawned. The beds (usually flat when this is the prodecure) are made immediately. These are fairly well moistened and compressed, then left to undergo a general fermentation, which may require a month. When the manure shows a tendency to fall to the temperature of the room it is spawned. Meanwhile, it will doubtless be found that a heavy crop of some small species of Coprinus will have appeared. The presence of this fungus is not injurious, but rather it may be taken as an indication that the conditions are favorable.

Ordinarily the manure is obtained as fresh as possible. It should include the straw used in bedding the animals, and the quantity 
of the straw will determine to some extent the value of the manure. The straw of cereals is far better than that of most other grasses. The more resistant straws seem greatly to improve the texture of the compost for mushroom purposes. Commercially it is a mistake to attempt to get the manure free from straw. If fresh manure is not obtainable, that which has been trampled by the animals is ordinarily rich, well preserved, and desirable. It ferments best in large piles, and these may be of considerable 'extent, about 3 or 4 feet deep throughout. If not uniformly moist, the material should be sprinkled. At no time is a very heavy watering desirable. In from four days to a week or more the compost should be turned, or forked over, and a second turning will be required a week or ten days later. Water should be added only when necessary to maintain a moist (but no twet) condition. With this amount of moisture, and with the piles deep enough to become fairly compact as a result of their own weight, there will be little danger of any injurious fermentation. During the normal fermentation the temperature may rise higher than $150 \mathrm{deg}$. F. In from fifteen to twenty-one days or more, depending upon the conditions, temperature will begin to fall, and the compost may be used in the construction of the beds. When used in the beds, it has ordinarily lost all objectionable odor, and the color of the straw has changed from yellow to brown.

It has been the experience of some of the most successful growers that the use of shavings for bedding material in the stables does not injure the value of the product for mushroom work. The presence of a large amount of sawdust is, however, objectionable so far as the writer's experience goes. Compost containing much sawdust is necessarily very "short," and therefore the physical condition is not the most favorable for Agaricus campestris.

In another chapter attention is called to the fact that the value of the manure depends to a considerable extent upon the feed given the animals. It would not be wise to depend upon that obtained from stables in which hay and green foods are used to too great an extent. Moreover, it is not believed that compost made from the manure of cattle barns in mushroom growing is as desirable as stable manure.

In some cities the municipal ordinances require that the manure shall be promptly removed from the feeding stables or that it shall be disinfected. In the latter case crude carbolic acid, or even corrosive sublimate, may be used to secure this end. Manure thus disinfected is, of course, undesirable for mushroom work. For the same reason the manure of veterinary hospitals is of questionable value.

For the most part manure may be composted in the open air. It may, however, be prepared with greater uniformity under cover. During midsummer, protection may be desirable on account of drying out, while in the winter it is more important in case of excessive cold. If it is necessary to compost manure during the winter, moreover, the piles should be of considerable depth. 


\section{Installation of beds}

Mushroom beds are of two general types, (1) the flat bed, frequently referred to as the English, and (2) the ridge bed, known as the French type. In making the former the entire floor space may be utilized as a bed, and the beds may be arranged in the form of tiers or shelves, as shown in the figure. In low cellars or caves, and; indeed, wherever the amount of floor space is not the most important consideration, it would be well to avoid the use of shelves; but where the amount of floor space is an important factor they may be adopted to a'dvantage, although the additional labor involved in the growing of a crop under such conditions is an item to be considered. When the shelves are used one should be careful to whitewash these after each crop, in order to avoid the increased danger from insect depredations. In any case, flat beds should be made from eight to ten inches deep.

Ridge beds enable one to get a somewhat greater surface space in a given area, but they are also more expensive, so far as the labor of construction is concerned. Nevertheless, under many circumstances they are obviously desirable. They should be about 2 feet wide at the base, tapering gradually to the apex, and not more than about 18 to 20 inches high when compressed and cased. The custom is to make two such beds in contact and then to leave a walk way of 8 or 10 inches between the next two, and so on till the space is occupied. Next to the walls slanting beds may be prepared.

In any case, the manure is made up in the form of the bed desired, and should be firmed or compressed up in the form of the bed desired, in order to prevent drying out and burning when the second fermentation takes place. At this time the manure should be neither wet nor dry, but merely moist. The only practical test of the proper moisture content of the manure which can be relied upon is when upon compression water can not readily be squeezed out of it.

The prevalent opinion among amateurs that the bed should always be deep enough to maintain a considerable heat is believed to be erroneous. Grown under more or less uniform conditions, mushrooms seem to require no bottom heat, and the bed should fall to the temperature of the room some time after spawning. Bottom heat, and hence large beds, are, however, desirable when sudden changes of weather would so reduce the temperature of the bed as to delay growth. Under similar conditions, as well as in dry air, mulching may be required.

\section{Spawning and Casing the beds}

From what has been said concerning the temperature requirements it will be evident that spawn should not be inserted in the beds until the temperature has fallen low enough to insure successful competi- 


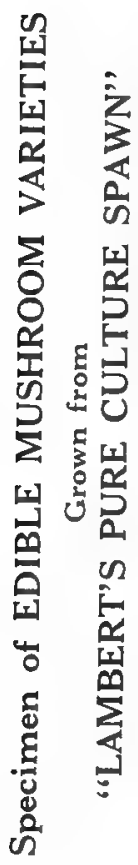

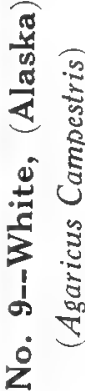



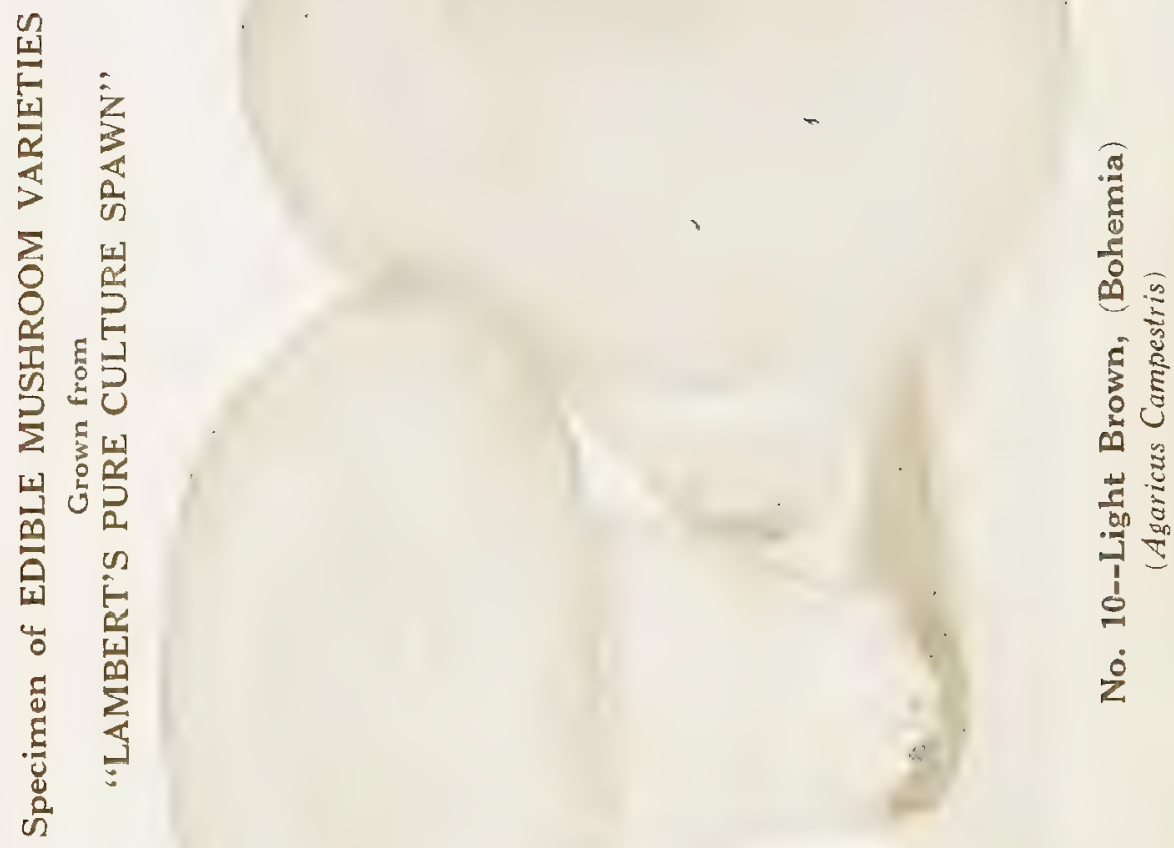
tion on the part of the mycelium with other organisms. In many articles on mushroom growing, it has been suggested that beds may be spawned when the temperature has fallen to about 90 deg. F. From experience and observation, the writer can only conclude that such a temperature is frequently fatal, and it is believed that the temperature of the beds should be permitted to fall to $70 \mathrm{deg}$. F. before being spawned. In fact, the most successful results have been obtained at temperatures from $65 \mathrm{deg}$. to $70 \mathrm{deg}$. F. It was formerly believed that if the spawn were inserted at $90 \mathrm{deg}$. F. this higher temperature incited the rather dormant mycelium to rapid and vigorous growth. It is clear, however, that the rapid development of the new mycelium from the pieces of spawn brick inserted is not so important a factor as suitable conditions for continued growth. If the temperature falls rapidly from $90 \mathrm{deg}$. F. after spawning, however, no injury may tesult. Nevertheless, it is to be considered an unfortunate condition.

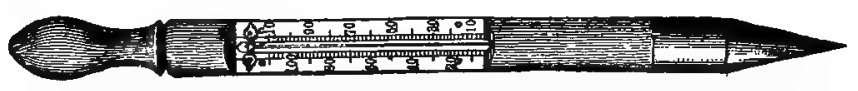

The bricks of spawn may be broken into from ten to twelve pieces, from 1 1-2 to 2 inches square. These pieces may be inserted about 1 inch beneath the surface of the manure. In flat beds they may be placed from 10 to 12 inches apart throughout the bed, and in ridge beds should be inserted on each side alternately, one near the top and the next near the bottom. It is well to insert the pieces vertically, as the mycelium does not then seem so readily to suffer damping off. After spawning, the beds should again be firmed, and they are then ready to be cased or loamed whenever this process may seem most desirable. At the time of spawning the beds should be in the best condition possible for the growth of the mycelium. Delay in growth at this time is one of the surest indications of a light yield. If the bed contains the proper amount of moisture, and if the walls and floors of the house or cellar are sprinkled occasionally, so as to maintain a moist condition of the atmosphere, it is possible to avoid wholly the use of water upon the beds immediately after spawning. In no case should a bed recently spawned be heavily watered. The surface may be sprinkled, if there is a tendency toward drying out. The same test for moisture content as has been outlined previously in these pages in the chapter on preparing the manure should be followed. The beds should become gradually somewhat drier, however, during the growth of the spawn.

The absolute water content for the bed at the time of spawning should be about 40 per cent, although this will vary considerably, according to the conditions, and especially with relation to the quantity of straw in the manure.

If the spawn grows rapidly at first and spreads throughout the bed, it will not be'injured by a slight drying aut, or by a temperature even as low as $32 \mathrm{deg}$. F. On the other hand, a continuous high 
temperature for several days, or excessive watering, is sure to result in an irreparable injury. In several instances where the experimental beds of the writer have been made during the late autumn and where a vigorous growth of spawn has been secured before the advent of the coldest weather, the beds have remained unproductive throughout the winter months, or so long as the temperature remained intermittently below $40 \mathrm{deg}$. or $50 \mathrm{deg}$. F. With the warmer weather, these beds have come into bearing several months later, and where the temperature has then remained favorable for some time a good yield has been obtained. In this case, moreover, the bed will bear much longer at a temperature of $60 \mathrm{deg}$. F. or above, than if the temperature has been constantly in the neighborhood of 60 $\operatorname{deg} \mathrm{F}$. throughout the growing season of the spawn. As a rule, beds thus filled with spawn and then subjected for a time to cold conditions yield at the outset much larger mushrooms than beds exposed to a more constant temperature, even if this constant temperature may be aptimum.

At any rate, the beds must be "cased" as soon as convenient after the spawn is inserted. As a rule, one should wait from one to two weeks in order to be sure that the spawn is growing. Casing consists in applying to the bed a layer of loam from 1 to $11-2$ inches deep. In France the casing soil consists usually of calcareous earth, sometimes mixed with loam. Ordinary loam of almost any quality will suffice. This should be secured in advance, and it is well to protect it from the weather, so that at a convenient time it may be worked over, and if necessary screened, in order to free it from large pebbles or tra,sh. When the loam is applied, it should, on ridge beds, be carefully firmed. When cased, a bed should require watering for the most part merely to maintain a moist surface.

\section{Watering}

As previously indicated, the spreading spawn should receive no water, or at least as little as possible. When, however, the mushrooms begin to appear, more water will be required, and a light sprinkling may be given once or twice each week, or as often as the conditions demand. Beds which come into bearing in proper condition should never be drenched. It has been found by experience that under the most favorable conditions a bed will require occasional sprinkling, since, owing to continual evaporation, there will be a gradual loss of water, at least after the mushrooms begin to appear. Sprinkling should be made after the mushrooms have been gathered, and the loam disturbed by the removal of the mushrooms should always receive a light sprinkling.

\section{Picking and Preparing for Market}

When a bed is in full bearing the mushrooms should be gathered at least once in two days, and it is well to pick them every" day, 
particularly if the temperature is up to $60 \mathrm{deg}$. F. or more. Picking is itself an art, and the intelligent owner will soon find that the yield of a bed may be greatly lessened by lack of judgment in picking. To satisfy the general demands of our markets at the present time it is not recommended to take the buttons; yet, if there is a fancy trade for these it should be met. Little or no gain of weight occurs in the mushroom, however, after the veil begins to break, so that mushrooms should not be left after this time. Flat tops are a thirdgrade article, but these, as well as all defective mushrooms, should be sedulously removed from the bed every day.

In picking, grasp the mushroom by the cap (a large one by both cap and stem,) twisting it to remove it easily from the soil. Where the mushrooms come up in large united clusters, it will be best to cut them, in order not to disturb the mycelial connections of all. Some good growers practice "cutting" throughout, but the stubs must decay and are a source of danger. - After all good mushrooms from a cluster have been taken, remove any fleshy spawn masses adhering and add fresh loam.

As they are picked the mushrooms are put into shallow baskets and taken to a sorting and packing table. The stems are cut off and any adhering loam is brushed from the cap. It is true that mushrooms keep somewhat better if the stub is left attached and the loam removed by rubbing, but except in. special cases this procedure is not to be recommended. It is not necessary to cut the stem off short, but the market demands that there shall be few long shanks.

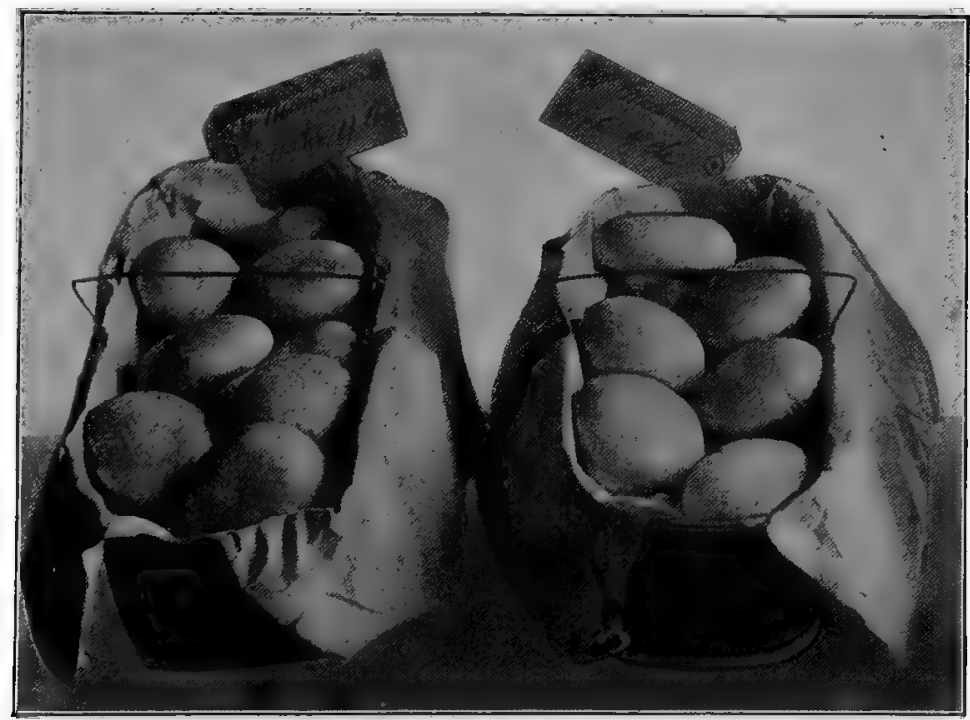

Four pounds Mushrooms in each basket. Grown from Lambert's Pure Culture Spawn. 
For the best trade it is desirable to "sort" the mushrooms, placing only those of nearly the same size in the same packages. It is certainly not well to pack together "broilers" and buttons, if this can be avoided. Defective mushrooms should invariably be thrown out. Mushrooms should be treated as a first grade product in every way, and therefore the package must be attractive. If the time involved in shipment is not to be very long, they may be put into 5 pound splintwood baskets, or they may be packed in 2 pound boxes arranged in crates as prepared for fruit. Shipment may also be made in boxes of sizes demanded by the general or private trade. Baskets afford excellent ventilation, yet boxes are often to be preferred. If the latter are lined with a blue paraffin or oiled paper, a good color contrast will result and the package will be made much more attractive.

Under favorable circumstances, a bed may come into bearing within six weeks. It usually requires, however, a longer period, and eight weeks may more nearly represent the average conditions. If the conditions have been variable, and especially if at times a very low temperature has prevailed, bearing may be still further delayed. Again, the period of production or the profitable "life" of a successful bed may vary greatly, ranging from five weeks to as many months. As a rule, a bed which produces fine heavy mushrooms will bear longer than one which yields plants of lighter weight. Many growers think that there is profit in a bed which yields one-half pound per square foot of surface area. One should not be satisfied with less than this, and if the best conditions prevail this yield is far below what should be obtained. Two pounds per. square foot is an excellent yield and some of our growers report this amount.

\section{Old Beds}

When a bed has ceased to bear, or is no longer profitable commercially, it should be taken down and every particle of the bedding and casing materials removed from the cave, cellar or house. The manure is still valuable for field and garden purposes, but it is wholly useless and even dangerous for mushrooms, because it is not only exhausted with reference to mushroom growing but may also harbor the diseases or enemies of the mushroom. When the bed is removed the house-should be thoroughly cleaned, and if possible, sprayed or fumigated. If conditions remain constant, there is then no reason why another crop should not follow immediately.

\section{Open Air Culture}

In some sections of England and France open air culture of mushrooms in beds is practicable during the late autumn and winter months in which case the productive period may extend into the spring. 
The difficulties in the way of open air culture are not merely those of maintaining a more or less uniform temperature, but also of maintaining practically constant conditions of moisture. For these reasons it is necessary to mulch the beds heavily with clean straw. In some instances a light mulch of straw is permitted to remain even during the period of production, for a rapid drying out of the surface would be hazardous or fatal. It is better, perhaps, to put the beds under some form of protection, such as an improvised cold frame.

In regions where the climatic changes are marked, open-air culture is probably not to be recommended during any season for commercial purposes. It is probable that there are some areas in the United States in which open-air culture might be practised with profit. It has seemed that certain sections of California might be favorable for this phase of the work. In the interest of experiments along this line the writer has made a special attempt to acquaint himself with the conditions in that section of the country. This has seemed particularly desirable, inasmush as fresh mushrooms could not be shipped to the far West from sections in which they are at present grown in quantity. From the information obtained it is thought that successful open air mushroom growing might be anticipated in those sections where the average temperature is between $48 \mathrm{deg}$. and $55 \mathrm{deg} . \mathrm{F}$., provided there are relatively few days when the temperature falls as low as $32 \mathrm{deg}$. F. At the same.time, open air culture cannot be recommended for those sections in which dry winds are prevalent. As a rule, during the wet or winter season the rainfall is so light that heavy mulching would probably suffice to prevent injury from excessive wetting. Nevertheless, it seems apparent that even in regions most favorable for open-air culture some inexpensive partial protection against the changes of temperature due to direct sunlight, or against heavy rainfall, would be desirable.

LAWNS AND PASTURES-Lawns and pastures may be inoculated by breaking a piece of spawn in four pieces and inserting the same under the sod about two feet apart. Plant in the summer and if the season is not too wet mushrooms will appear in the fall. Ayoid depressions where water would remain stagnant, as an excess of moisture destroys the spawn. Since weather conditions render open air culture rather uncertain, the use of fresh high grade spawn might be considered expensive. It is often possible, in such case, to obtain from dealers at a much reduced price, spawn which has been kept in stock for some time and cannot therefore be sold as strictly fresh. The grower, thus incurring no expense in the preparation of beds, runs no chance beyond the small outlay for the spawn.

\section{Mushroom Enemies}

Under suitable conditions and with the exercise of constant vigilance as to general cleanliness the mushroom bed will seldom fail as a result of diseases or insect depredations. Nevertheless, every 
precaution should be taken to avoid these difficulties. Some of the most common troubles reported in this country are as follows:

FogGING OFF-During the pin-head or button stage, and sometimes even later, the mushrooms which may be appearing in quantity, turn brown, cease to grow, and soon decay: This is supposed to be a physiological trouble; that is, one caused by a lack of essential conditions. Molds and bacteria may play a secondary part at least in producing this disease. It is most frequent in warm weather.

BLACK SPOT-This disease manifests itself by the appearance of small discolored areas on the surface of the cap. It is said to be due to improper watering and to lack of proper ventilation.

Fungous Diseases-There are several fungous diseases of the mushroom, none of which, however, has been of serious importance in this country, and reference to them may, therefore, be omitted in this place.

Mires-There are one or two species of mites constantly to be found in compost heaps, which may be injurious in the mushroom bed. They are seldom troublesome at a temperature of less than $50 \mathrm{deg}$. F., as they are then more or less sluggish; and, although they may be found upon the mushroom, they do little or no harm. At a higher temperature they are supposed to destroy the spawn to a certain extent and owing to their great numbers, they are at least objectiontable upon the mushrooms.

Wood Lice, or "Sow Bugs."-These crustaceans, like the mites, are not of great importance where the conditions of temperature are favorable. The best methods of extermination are by trapping and poisoning them. This may be done by putting pieces of potato smeared with arsenic or Paris green, together with some dry rubbish, into tin cans or boxes placed on the side. Most of the sow bugs that enter these receptacles will be killed by eating the poison.

SNaIls--Snails and slugs are frequently pests in mushroom growing, but they may be readily trapped by the use of lettuce or cabbage leaves.

SPRINGTAILS - Springtails may become a source of great annoyance when mushrooms are grown in damp caves. As a rule, they can only establish themselves when carelessness has been shown in cleaning out old bedding material. When once established they mul- 
tiply very rapidly, and the mushrooms are attäcked by them in such numbers that within a day or two every appearance of fogging off is made manifest. These insects may be readily. destroyed by fumigation with carbon bisulphide, but prevention is the wiser course.

LARVAE of Flies - With good manure and under suitable conditions larvæ of mushroom flies are not usually injurious. Nevertheless, the larvæ of the little fly, Phora minuta, may be troublesome in warm weather. Fumigation, as previously suggested, may be of service in order that the life of a bed may be extended somewhat later into the warm season.

\section{Mushroom Spawn}

The mycelium of the cultivated mushroom has long been known commercially as "spawn." From early times it has been recognized that mushrooms may be grown from spawn, and it is quite certain that in all attempts to propogate mushrooms spawn has been used for the purpose.

A "Chance" Method-For practical purposes it is necessary to renew the spawn and to secure, if possible, spawn which has not previously weakened itself by the production of mushrooms - known as virgin spawn. Natural virgin spawn may be found wherever "in nature" it has been possible for the spores to germinate and to produce a mycelium.

Many attempts have been made by practical growers to develop spawn from spores, sowing the gill portions of mature mushrooms in specially constructed heds; but the results, so far as the writer is aware, have not been satisfactory. As a rule, therefore, growers have been compelled to rely wholly upon a virgin spawn which has been obtained by chance. It is said that in the vicinity of Paris some persons make a business of searching for this virgin spawn, which they sell to the growers at a high figure.

However adept persons may become in the identification of various varieties of spawn by odor, etc., this must be considered essen- . tially a chance method.

A "Selective" Method.-From what has been said it will be perceived that very little advancement could be made in the selection of desirable varieties of mushrooms, in varietal improvement and the like, so long as the chance method of securing spawn should prevail.

The successful germination studies with chemical stimulation mentioned in this paper were soon overshadowed by the discovery 
of the method of making tissue cultures. The use of the latter method has been the means of a sudden advancement in spawn making in this country during the past two years, for many practical men have been quick to see the advantages which it offers.

The pure culture method of making virgin spawn is not one which will prove successful in the hands of wholly inexperienced persons, or of those who are unwilling to spend time and use the utmost care in the manipulation of the cultures and the culture material. The use of pure-culture methods necessitates to a considerable extent a knowledge of the bacteria and molds which are everywhere present in the air and which are especially abundant wherever there are dusty or damp, moldy conditions.

\section{The Vitality of Mushroom Spawn}

Many of the early experiments in mushroom growing undertaken by the writer were made in the hope of bring able to ascertain the more frequent cause of failure and some of the chief difficulties encountered by American mushroom growers. The ordinary commercial (English) spawn used by amateurs, that is, such as is obtainable upon the market during the winter months, was purchased wherever possible. Samples of this spawn were placed under conditions which were supposed to be most favorable for growth. Nevertheless, in the majority of cases there was no indication of the development of a new mycelium from the bricks of spawn thus obtained.

Special importations of some of the commercial English and French spawns were made, and this was packed, shipped, and stored under conditions as favorable as may ordinarily obtain. This spawn was imported during the mid-winter and sorted until March or early April, when it was used in spawning some experimental beds. The conditions of the experiments were practically the same throughout. yet in not more than half the beds was there a favorable development of mushroom spawn.

\section{The Storage of Spawn}

It is possible to ruin good spawn by improper storage, even in a relatively short period of time. Spawn should be kept in a place that will be both cool and dry, but never hot and dry. This should be remembered by both seedsmen and growers, for many failures may, undoubtedly, be attributed to the improper starage to which the material has been subjected."

From the reports of Dr. B. M. Duggar, Professor of Botany at the University of Columbia, and Collaborator of the Bureau of Plant Industry, U. S. Department of Agriculture. 
Specimen of EDIBLE MUSHROOM VARIETIES

Grown from

"LAMBERT'S PURE CULTURE SPAWN"

No. 11--Cream, (Columbia)

(Agaricus Arvensis) 
Specimen of EDIBLE MUSHROOM VARIETIES

Grown from

"LAMBERT'S PURE CULTURE SPAWN"

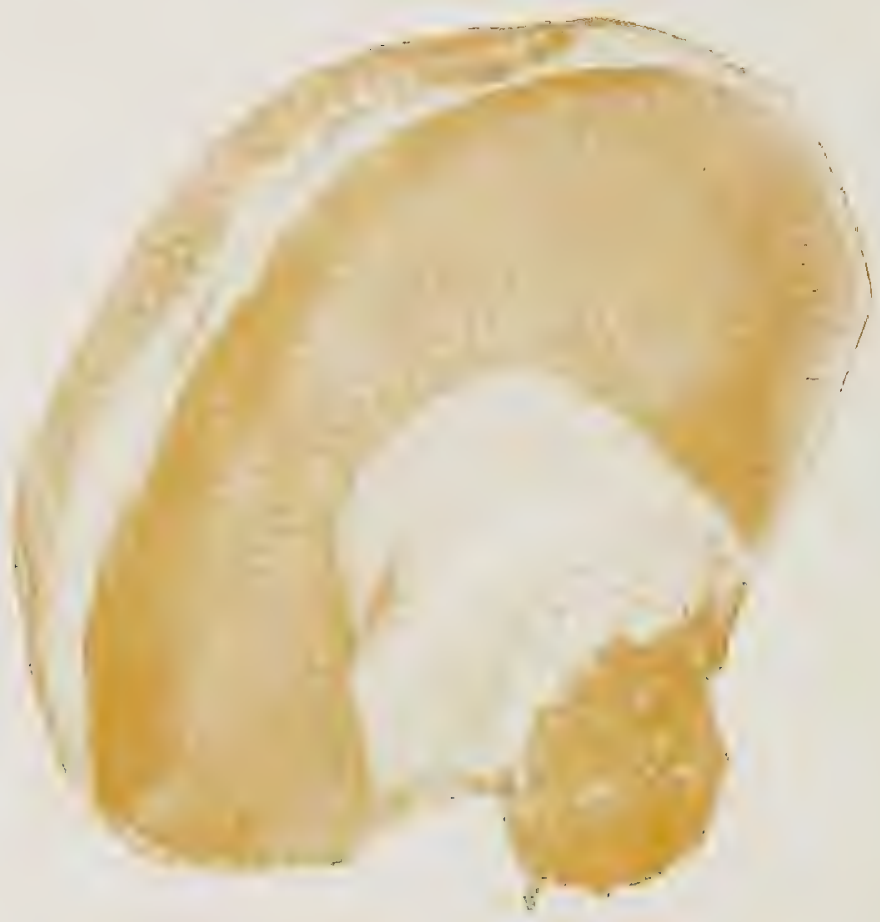

No. 12--Cream, (Columbia)

(Agaricus Villaticus) 


\section{Pure Culture Spawn}

The advent of pure culture (or tissue and spore culture) spawn marks an epoch in the history of mushroom culture. The importance of its discovery was immediately realized by the Department of Agriculture, who in turn brought it to the attention of the American growers. Selection and improvement in the varieties of the cultivated mushroom are now possible. Where formerly the grower was compelled to buy wild seed (English or French spawn), manufactured" by the "chance" method, he is now in a position to buy pure culture spawn of the variety most suited to his markets and to the special conditions surrounding him.

Pure culture spawn bears to English, French, and other wild spawn the relation that grafted or budded trees bear to fruit seed. 'The present method of manufacturing English and other wild spawn consists in gathering the mycelium wherever nature happens to have deposited it in its wild state, and "running" the same into bricks. No one, not even the manufacturer of this spawn, is able to tell what variety or varieties of mushrooms it will grow, in fact wild spawn contains a miscellaneous lot of varieties. Since a comparatively small number of those are susceptible of cultivation at all, it is not at all surprising that so many experienced growers using foreign spawn are continuously meeting with total or partial failures in spite of their most intelligent efforts.

Proceeding by selection and elimination, the pure culture method of manufacturing spawn admits of steady improvement in the varieties. Cultures are taken from choice specimens of desirable varieties known to be thoroughly acclimatized and selected with special reference to their hardiness, size, flavor, appearance, and prolificness.

"Lambert's Pure Culture Spawn," grown by this "selective" method and manufactured by the American Spawn Company, St. Paul, Minn., was placed on the market immediately following the discovery of the pure culture method. Controlling nearly three acres of mushroom beds, this company possesses the all-important advantage of unlimited selection for its cultures. Only perfect specimens thoroughly acclimatized and capable of successful cultivation are used. Every brick of its spawn is inspected before it leaves the yards, and none but the very best are shipped. "Lambert's Pure Culture Spawn" is, therefore, sure to "run" and produce a uniform and vigorous crop of a desirable variety of mushrooms, to the exclusion of other and inferior fungi.

\section{How and When to Order Spawn}

When your beds have reached the proper condition to be spawned, a delay of a few days is sure to be injurious, if not disastrous to your crop. The loss of temperature and moisture, incident to this 
delay, cannot be retrieved, and a measly crop or perhaps a failure is the inevitable result.

It is a mistake to suppose that your dealer is always prepared to fill a rush order for spawn, and especially Pure Culture Spawn. The demand for Pure Culture Späwn, at present and for some time to come, will exceed the supply, and dealers can only obtain it from the manufacturers in limited quantities by placing their orders in advance and in excess of their needs. A careful grower will place his order with his dealer at least sixty days before his beds are expected to be ready for the spawn. If, as is often the case the dealer has not in stock the kind of spawn or variety desired, he should be given time to order a fresh supply. Rush orders are filled with any stock on hand.

A good method is to first address an inquiry to your dealer, asking if he will be able to supply you with "Lambert's Pure Culture Spawn" of the American Spawn Co., St: Paul, Minn., naming the variety wanted, and whether or not he can positively make delivery on or before a specified date (giving him from 30 to 60 days). This will give him time to procure a fresh stock, if not on hand, and at the same time indicate to him where to procure it. On a time order the chances are that you will receive the freshest spawn, specially ordered for your purpose, while the old stock will be kept on hand to meet the rush orders. In fact, where orders are for one or more full cases, dealers may have shipments made direct to the grower from our warehouses in Philadelphia or in St. Paul. In this manner mistakes or substitution are avoided and fresh spawn guaranteed.

Realizing that the discovery of Pure Culture Spawn will soon result in the abandonment of English and other forms of wild spawn, some importers of foreign wild spawns have attempted to meet the situation by offering, at a reduced price, English spawn under the name of "English Pure Culture Spawn." They are unable, however, to name the specific variety of mushrooms which this so-called "English Pure Culture" spawn will produce. Since this is the fundamental distinction between pure culture spawn and wild spawn, the deception is easily exposed.

\section{Price of Pure Culture Spawn}

Pure Culture Spawn is more expensive than the old-fashioned English or wild spawn for the same reason that grafted trees cost more than wild seedlings. But the small additional outlay for the seed is repaid manifold in the abundance and quality of the crop, and the grower is absolutely certain that he is not. raising poisonous or undesirable varieties. An intelligent farmer could not be induced to plant wild seed, even if given to him, when improved seed is available. 
Lambert's Pure Culture Spawn is now kept in stock by the leading seedsmen of the United States and Canada, and while the retail price may vary with different dealers, the following schedule is generally followed:

STANDARD Bricks

(Estimate one brick for about eight square feet of beds.)

1 brick, by mail, postpaid.

2 bricks, by mail, postpaid

5 bricks, by express, not prepaid.

10 bricks, by express or freight, not prepaid . . . . . . . . .

25 bricks, by express or freight. not prepaid............

50 bricks, by express or freight, not prepaid

* 80 bricks, (one-half case), by freight, not prepaid

100 bricks. by express or freight, not prepaid . . . . . . . .

160 bricks, (one full case) by express or freight, not prepaid...

$\begin{array}{cc}\begin{array}{c}\text { East of } \\ \text { Missouri River }\end{array} & \begin{array}{c}\text { West of } \\ \text { Missouri River }\end{array} \\ .40 & \$: 40 \\ .70 & .70 \\ 1.00 & 1.20 \\ 1.80 & 2.00 \\ 4.25 & 4.80 \\ 8.00 & 9.00 \\ 12.00 & 13.50 \\ 15.00 & 17.00 \\ 22.40 & 24.00\end{array}$

Should your dealer be unable to supply you, please advise us, mentioning his name and enclosing remittance according to the above scale of prices. We will then transmit your order for immediate shipment to some other reliable dealer in your neighborhood whom we know to be supplied with a fresh stock of "Lambert's Pure Culture Spawn."

One brick of "Lambert's Pure Culture Spawn" weighs from 1 1-4 to 1 1-3 pounds, and will be sufficient to spawn about one square yard of bed.

The prices above given are for the standard varieties of the cultivated mushrooms which are herein mentioned or illustrated.

Bricks of "Lambert's Pure Culture Spawn" are of two kinds, standard bricks and direct bricks. The "standard brick" is inoculated from a pure culture transfer. The "direct brick" is inoculated directly from the pure culture, as raised in the laboratory, without intermediate transfer.

By reason of the increased laboratory work involved, an additional charge of 3 cents per brick above the price of standard bricks is made for the direct bricks. Growers should bear in mind this distinction in ordering from dealers and specify the kind of bricks wanted.

\section{Pure Culture Varieties}

The following standard varieties of Lambert's Pure Culture Spawn have been developed and placed on the market.

\section{Agaricus Campestris}

Catalogue No. 5, Brown (Bohemia), prolific, grows in clusters, (Not illustrated.)

Catalogue No. 6, White (Alaska), similar to No. 9, heavier stem. (Not illustrated.) 
Catalogue No. 7, Brown (Bohemia), a hardy variety and good producer, very heavy. (Illustrated.)

Catalogue No. 8, Cream White, a hardy variety, pretty shape and prolific, to be preferred for summer planting. (Illustrated.)

Catalogue No. 9, White (Alaska), a good seller in eastern markets. (Illustrated.)

Catalogue No. 10, Light Brown (Bohemia), a heavy and fleshy mushroom. (Illustrated.)

\section{Agaricus Arvensis}

Catalogue No. 11, Cream (Columbia), very similar to No. 8 , but larger and slightly darker. (Illustrated.)

\section{Agaricus Villaticus}

Catalogue No. 12, Cream (Columbia) large and very fleshy. (Illustrated.)

Careful tests and experiments in the development of other varieties, including the "Morel" (Morchella Esculenta) and the giant Puffball, are under way, while the varieties already developed are being steadily improved.

\section{Trade Mark}

To guide against substitution and for other reasons whicli may be surmised, we are compelled to hereafter stamp each brick of "Lambert's Pure Culture Spawn" with our trade mark, the letters $\mathrm{PC}$ enclosed in a diamond, (not a circle, heart or square).

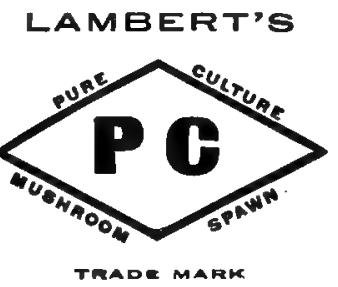

Growers will confer a favor upon us by advising us of every instance where our spawn cannot be procured from a reliable seedsman or where they suspect that other spawn has been substituted. We don't sell or ship any but fresh and high-grade spawn and, with the co-operation of the reliable dealers, it is our aim to pro- 


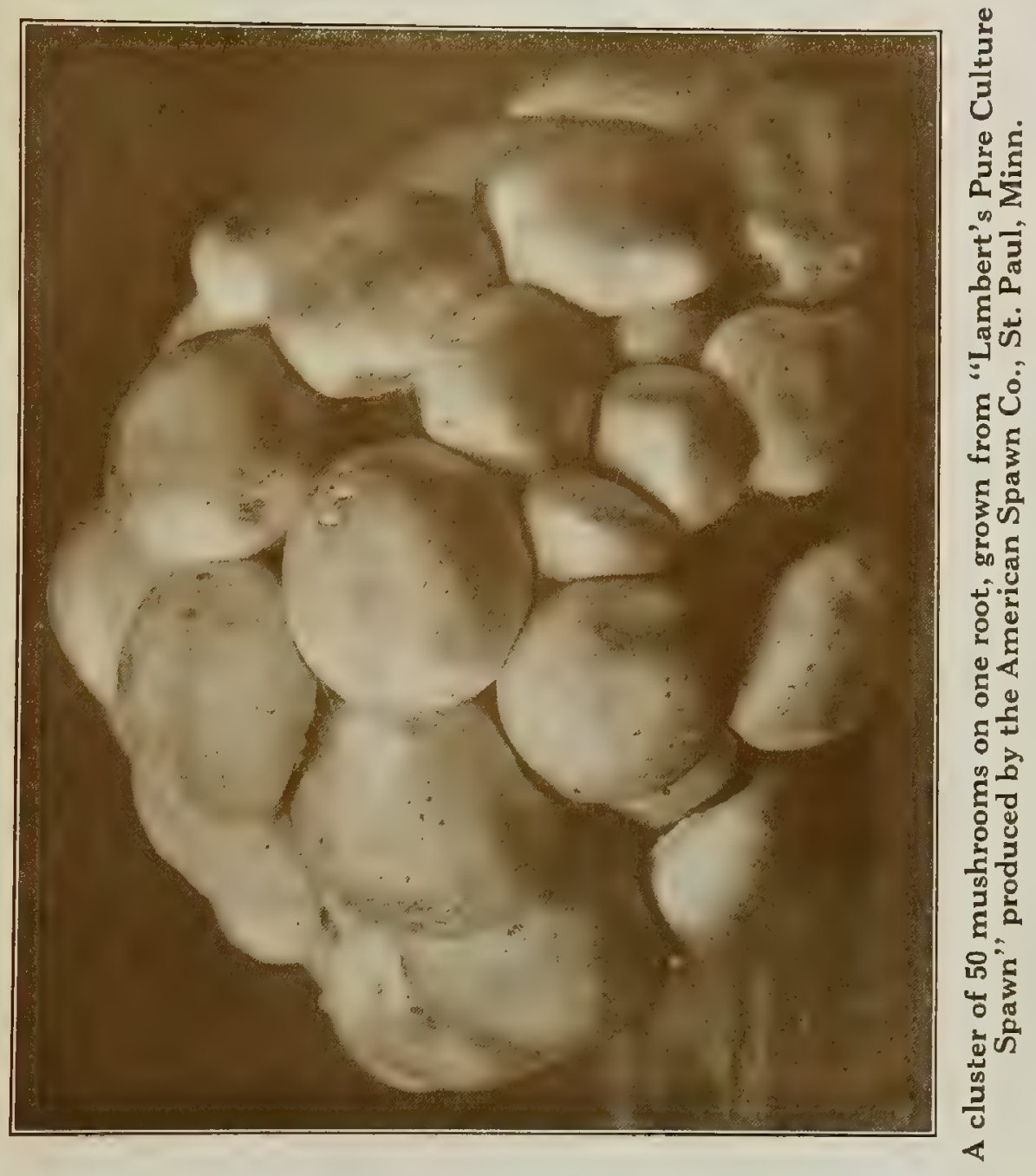



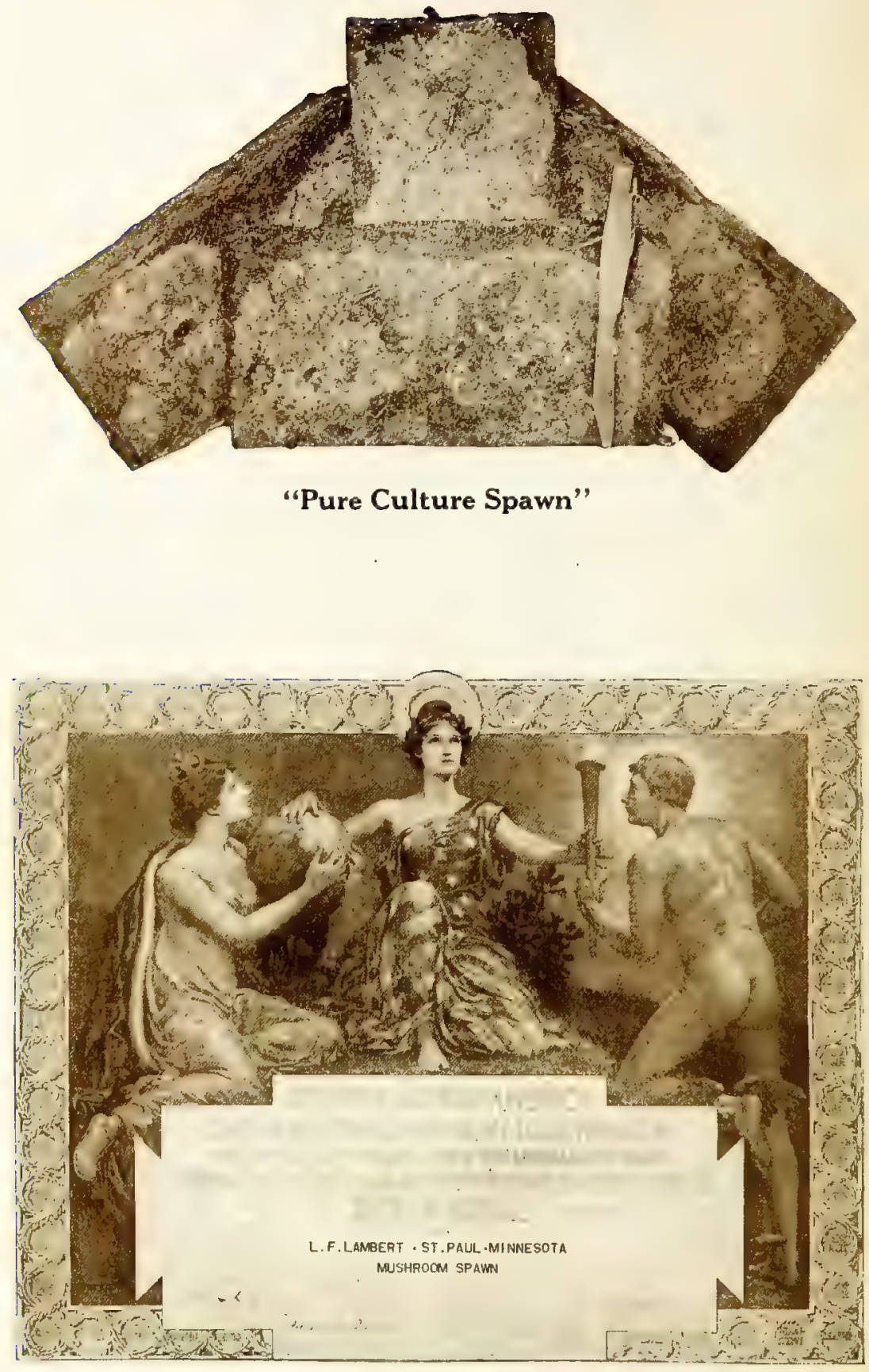

Highest Award Universal Exposition, St. Louis, 1904 
tect the growers against the discouraging failures and losses which are frequently imposed upon them by unscrupulous persons in the sale of stale or worthless spawn.

\section{Special Hints on Cultivation}

MOISTURE.-The mushroom demands a moist atmosphere, and yet the direct application of water to the growing crop, and especially to the young spawn, is always injurious. To overcome this difficulty it is recommended to sprinkle, at frequent intervals, the walls, floors, boards, etc., surrounding the beds. If water is applied to the beds, it should be distributed in a fine spray. The beds should be moist, but not wet.

VENTILATION.-Fresh air is essential to the perfect and healthy development of the mushroom crop, but draughts are to be strictly avoided. Draughts cause too rapid evaporation of the beds, which cannot well be restored to a moist condition except by the direct and more or less injurious application of water in quantities. Draughts will also injure the growing crop of mushrooms, causing the caps to check and crack, and to assume a darker color. This may, in a measure, explain why a bed of white mushrooms will sometimes darken as the crop advances, the beds having lost too much moisture by evaporation. In a dry atmosphere, a short and imperfect crop only can be gathered.

CASIN G.-Many growers, especially beginners, make the mistake of casing their beds too soon, often immediately after spawning. If, for any reason, the bed is not in a condition favorable to the development of the spawn, the casing under these circumstances will aggravate the evil and kill the young spawn. Should the bed be too wet or too acid when spawned, a delay in the casing will allow the surface to evaporate or oxydize enough to start the spawn. The loam should therefore not be applied until the spawn is observed to run well in the beds. It must not, however, be inferred that the casing can be dispensed with or even delayed too long. Without a casing of loam, spawn will not head. It will continue to run in the beds until it dies. The loam furnishes the medium unfavorable to the further development of the spawn, which causes it to head and come to fruition.

\section{An Easy Method for the Amateur}

The complex questions involved in the successful cultivation of the mushroom often discourage the beginner. For the benefit of amateurs, who principally desire immediate results with least amount of trouble, we recommend the following method: 
Mix in a barn or shed, where material will not freeze during the manipulation, 6 bushels fresh horse manure, free from long straws, with two bushels of good garden loam. Manure should be fresh, not dried, and loam should be moist. If material is fresh no addition of water is necessary. Leave a few days, provided there is no danger of hard frost, which would freeze the material in to cakes.

Build a small box or partition in your cellar 1 yard square, 12 inches high. Bring in the material and spread one bushel at a time evenly in the box; tamp it firmly with a brick. Then bring in the next bushel, and so on.

Ascertain the temperature of the bed at frequent intervals, using a dairy thermometer or special mushroom thermometer. When temperature of the bed has fallen to 75 degrees $F$., plant the spawn, breaking the brick into 8 or 10 pieces, inserting a piece in the center of each square foot of bed, 2 inches below the surface. Cover and tamp the holes. Then cover the bed with about 4 inches of clean straw, and if convenient, with an old piece of carpet.

After 10 or 12 days remove the straw and spread 1 to $1 / 2$ inches of fresh loam over the bed, tamp gently and replace the straw and carpet. After about 40 days mushrooms will commence to appear. The temperature of the cellar should nor rise above $60 \mathrm{de}-$ grees nor fall below 50 degrees $F$.

The quantities above mentioned are based upon one square yard of bed for which one brick of "Lambert's Pure Culture Spawn" is required. For larger beds increase the quantities proportionately.

\section{How to Cook Mushrooms}

To the true epicure there are but four ways of cooking mushrooms-broiling, roasting, frying them in sweet butter, and stewing them in cream.

In preparing fresh mushrooms for cooking, wash them as little as possible, as washing robs them of their delicate flavor. Always bear in mind that the more simply mushrooms are cooked the better they are. Like all delicate flavored foods, they are spoiled by the addition of strongly flavored condiments.

BROILED MUSHROOMS.-Select fine, large, flát mushrooms, and be sure that they are fresh. If they are dusty, just dip them in cold salt water. Then lay them on cheese cloth and let them drain thoroughly. When they are dry, cut off the stem quite close to the comb. Or, what is better, carefully break off the stem. Do not throw away the stems. Save them for stewing for soup or for mushroom sauce. Having cut or broken off the stems, take a sharp silver knife and skin the mushrooms, commencing at the edge and finishing at the top. Put them on a gridiron that has been well 
rubbed with sweet butter. Lay the mushrooms on the broiling iron with the combs upward. Put a small quantity of butter, a little salt and pepper in the center of each comb from where the stem has been removed, and let the mushroom remain over the fire until the butter melts, Then serve them on thin slices of buttered and well browned toast, which should be cut round or diamond shape.

Serve the mushrooms just as quickly as possible after they are broiled, as they must be eaten when hot. So nourishing are broiled mushrooms that with a light salad they form a sufficient luncheon for anyone.

FRESH MUSHROOMS BAKED.-The following is Juliet Carson's recipe for baked mushrooms, and it is an excellent one:

Carefully cleanse the mushrooms as in the directions for broiling. Cut as many slices of bread as there are mushroom caps, trimming off the crust, and having each slice about two inches square. Lay the slices of bread in a baking pan and spread each slice with butter. Sprinkle each slice with a little salt and pepper. Next put on each slice of bread one or two mushrooms-just enough to cover the bread. Put the pan in a hot oven for five minutes. Then draw the pan to the front of the oven and season the mushrooms with salt and pepper and put a piece of butter as large as a hazel nut in each mushroom cap. Return the pan to the oven and finish baking the mushrooms, which are done as soon as tender. Serve them on the bread on a very hot platter.

FRIED MUSHROOMS.-Clean and prepare the mushrooms as for broiling. Put some sweet, unsalted butter in a frying panenough to swim the mushrooms in. Stand the frying pan on a quick fire, and when the butter is at boiling heat, carefully drop the mushrooms in and let them fry three minutes, and serve them on thin slices of buttered toast.

Serve a sauce of lemon juice, a little melted butter, salt and red pepper with fried mushrooms.

STEWED MUSHROOMS-Stewed mushrooms after the following recipe make one of the most delicious of breakfast dishes. It is not necessary to use large mushrooms for stewing-small button ones will do. Take the mushrooms left in the basket after having selected those for broiling, and also use the stems cut from the mushrooms prepared for broiling. After cleaning and skinning them put them in cold water with a little vinegar, and let them stand half an hour. If you have a quart of mushrooms, put a tablespoonful of nice fresh butter in a stew pan and stand it on the stove. When the butter begins to bubble drop the mushrooms in the pan, and after they have cooked 'a minute season them well with salt and black pepper. Now take hold of the handle of the stew,pan and, while 
the mushrooms are gently and slowly cooking, shake the pan almost constantly to keep the butter from getting brown and the mushrooms from sticking. After they have cooked eight minutes pour in enough rich, sweet cream to cover the mushrooms to the depth of half an inch, and let them cook about eight or ten minutes longer. Serve them in a very hot vegetable dish. Do not thicken the cream with flour or with anything. Just cook them in this simple way. You will find them perfect.

$M U S H R O O M S T E W-P e e l$, cut up and wash. Stew in a little butter with red pepper, salt and a very little garlic. When soft add the milk and allow to stew some more. Set off the fire and beat a few eggs in the stew. Serve.

MUSHROOM PATTIES-Mushrooms are now often served at fashionable parties in the form of patties, very much on the style of oyster patties. Peel and cut in small pieces two pounds of nice fresh mushrooms. Add one-half cup of butter, pepper and salt, and one cup of rich, sweet cream. Stew for 12 minutes. When done sprinkle a small tablespoon of flour over them to thicken. This will fill about 20 patties.

MUSHROOM SANDWICHES-Peel one pound of mushrooms and chop real fine. Stew for 10 minutes with butter, the size of an egg, and pepper and salt.

Toast about 20 thin slices of bread. Butter them and insert the hot stewed mushrooms. Trim the crust and cut diagonally in the shape of triangles. Serve real hot.

DEVILED MUSHROOMS-Chop one quart of mushrooms, season with salt and pepper, and a little lemon juice; mix the yolk of two hard boiled eggs and two raw ones, stir in a pint of bread crumbs and a tablespoonful of butter. Fill baking-shells with the mixture, cover with bread crumbs and bits of butter. Bake a nice brown.

MUSHROOMS AND TOMATOES-Toast some slices of bread, cut them into round pieces two inches in diameter, and butter them. Peel some firm tomatoes, cut in thick slices, and lay them on the toast. On top of each place a peeled mushroom. Put them in a dish that can go on the table, pour a little clarified butter over them, put them in a hot oven for five or eight minutes, baste well and serve.

BROWN MUSHROOM SAUCE-Make a brown sauce, add to it one pint of fresh common mushrooms, simmer gently for fifteen minutes. Take from the fire and add wine if you use it. Some think a little mace or nutmeg an improvement, or a little Harvey sauce. 
CREAM MUSHROOM SAUCE-Make a sauce, and add one cup of fresh common mushrooms chopped fine, cook in a double boiler for ten minutes. Stems chopped fine may be used for this sauce.

MUSHROOM SOUP-Take a good quantity of the mushrooms, cut off the lower ends, and wash and peel, then put them in stew-pan with butter, pepper and salt and a little stock, stir until tender, take off and chop in small pieces; prepare a good stock as for any soup, and add it to the mushrooms and the liquor they have been stewed in. Boil all together and serve. The stems only may be used for this soup with success.

ROASTED MUSHROOMS-Cut the larger specimens into fine pieces and place them in a small dish, with salt, pepper and butter to taste; put in about two tablesponfuls of water, then fill the dish with half-open specimens and buttons; cover tightly and place in oven (which must not be overheated,) for about ten of fifteen minutes. The juice of the larger mushrooms will keep.

ESCALLOPED MUSHROOMS-Make a sauce of one tablespoonful of butter and one of flour, and two cupfuls of chicken broth or white stock; add to this the chopped stalks of a pint of mushrooms; reduce the same one-half, add a tablespoonful of chopped parsley, pepper and salt. Turn this sauce in to a shallow baking dish, put in as many mushrooms as will fill the dish, placing them close together, gills up, put a piece of butter on each and sprinkle the tops with crumbs and place in an oven for ten minutes, or until tender and serve hot.

CURRIED MUSHROOMS-Stew a quart of button mushrooms for about twenty minutes in enough good stock to cover them well, add a tablespoonful of butter, thicken with a teaspoonful of curry powder and a tablespoonful of flour, boil slowly for ten minutes longer, and just before taking from the fire add half a cupful of cream; serve hot on a dish with slices of toast.

MUSHROOMS A LA BORDELAISE-Choose some big, firm fresh mushrooms; peel, wash and drain them; make one or two slits on the top side of the mushrooms. Soak for an hour and a half in fine oil; pepper and salt. Broil them, turning when half cooked, so that each side may be equally broiled. Warm the oil in which the mushrooms have been soaked. Season with finely chopped onion and parsley. Dish the mushrooms and sprinkle with a few drops of vinegar or lemon juice, and pour the hot oil over them. 


\section{How to Preserve Mushrooms}

DRIED MUSHROOMS-Take medium sized mushrooms, wash and peel them for immediate use. Place them for a few moments in boiling water to which has been added a little vinegar or lemon juice, to keep the mushrooms from turning black. It is claimed by. some that distilled water is preferrable. The use of salt must be avoided on account of its hygrometric properties. The mushrooms being taken from the boiling water, are drained and then strung up on stout twine, bead like, in a shed or well ventilated room. Except in warm or dry climates, desiccation must be completed by placing the mushrooms in a moderately heated oven. In drying, the mushroom loses more or less of its flavor or aroma. Before using dried mushrooms they are first soaked in lukewarm water.

MUSHROOM CONDIMENT-Proceed as above, but force the desiccation. The dried mushrooms are then reduced to powder on a fine rasp, and preserved in closed jars. The powder of several varieties mixed with 5 or 10 per cent of truffle powder prepared in the same manner, forms a condiment which is greatly esteemed by epicures.

MUSHROOMS IN OIL-Peel and prepare the mushrooms as. above, bleach in boiling water and drain. Place them in a jar and fill with olive oil or melted butter. When the jar is cool it is sealed and stored in a cool place. Though more expensive this process preserves the flavor and aroma of the mushroom.

MUSHROOM KETCHUP - Take two pounds of fresh mushrooms, clean and peel them carefully. Cut in very thin slices and dispose in an earthern dish, each layer sprinkled with fine salt. On the top layer spread about four tablespoons of fresh walnut husks, finely chopped. Allow to macerate for four or five days in the cellar. When nearly melted pass through clean cloth. Reduce on slow fire to about half its volume; add its weight of calf's feet jelly, season with pepper and laurel and reduce to consistence of jelly. Preserve in a cool place.

PRESERVED MUSHROOMS-Lambert's Process-Take fresh clean mushrooms, peel and place them in cold water containing $1 / 2$ pound salt to the gallon, this is to prevent discoloring. Drain off the water and stew the mushrooms until they have reduced in bulk about 40 per cent. This only takes a few minutes. Put up in jars and cover the mushrooms with their own juice (for commercial purposes drain off the juice and fill with clear boiling water, this gives them a white appearance,) screw on the cover loosely, boil for 30 minutes and immediately screw the cover tight. Stand the jars 
on their head for 24 hours to detect leakage, then boil again for one hour. This second boiling should be done exactly 24 hours after the first. The leaking jars should be processed over again. The glass jars should be protected from direct contact with the bottom of the boiler.

\title{
26. Poisonous and Edible Mushrooms
}

\author{
By Dr. W. G. FARLOW, Harvard University.
}

The difference between the common edible mushroom and the fly agaric and deadly agaric, which the reader can easily remember, are as follows:

(1) The common mushroom has a pileus which is not covered with wart-like scales; gills which are brownish purple when mature; a nearly cylindrical stalk, which is not hollow, with a ring near the middle, and without a bulbous base sheathed by a membrane or by scales.

(2) The fly agaric has a pileus marked with prominent warts; gills always white; a stalk, with a large ring around the upper part, and hollow or cottony inside, but solid at the base, where it is bulbous and scaly.

(3) The deadly agaric has a pileus without distinct warts; gills are always white, and a hollow stalk, with a large ring, and a prominent bulb at the base, whose upper margin is membraneous or baglike.

(4) Other minor points of difference are the different places in which these species grow, and also the colors, which, although they vary in each case, are brilliant yellow or red in the fly agaric, white varying to olive in the deadly agaric, and white usually tinged with a little brown in the mushroom.

(5) A word should be said as to the size and proportions of pileus and stalk in these three species. In the mushroom the pileus averages from 3 to 4 inches in breadth, and the stalk is generally shorter than the breadth of the pileus and comparatively stout. The pileus remains convex for a long time, and does not become quite flat topped until old. The substance is firm and solid. In the fly agaric the pileus, at first oval and convex, soon becomes flat and attains a breadth of 6 to 8 inches and sometimes more. The stalk has a 
length equal to or slightly exceeding the breadth of the pileus, and is comparatively slenderer than in the common mushroom, but nevertheless, rather stout. The substance is less firm than in the common mushroom.

(6) The pileus of the deadly agaric is thinner than that of the common mushroom, and, from being rather bell-shaped when young, becomes gradually flat-toppéd with the center a little raised. In breadth it is intermediate between the two preceding species. The stalk usually is longer than the breadth of the pileus, and the habit is slenderer than in the two preceding species. All three species are pleasant to the taste, which shows that one cannot infer that a species is not poisonous because the taste is agreeable. The fly agaric has scarcely any odor. The other two species have certain odors of their own, but they cannot be described.

\section{Our Publications}

Earnest co-operation and a candid exchange of views between the spawn manufacturer, the dealer and the grower will result in mutual advantage and protection. It is our purpóse to compile and publish from time to time the latest information on the subject of mushroom culture and mushroom spawn, together with the results of practical experiments: We would therefore welcome any suggestions or criticism on the part of the growers and dealers which may be of interest or value. Our exceptional facilities permit us to give any reasonable suggestion a practical test, and to impart to the growers generally the information thus acquired.

Growers or amateurs who are sufficiently interested in the subject of such further publications will be entered on our free mailing list upon receipt of their name in full, with postoffice address, together with the name and address of their dealer. A change of address should be promptly communicated to the American Spawn Company, St. Paul, Minn. 


\section{Suggestions to Dealers}

1. Storage. It should be remembered by both seedsmen and growers, that many failures may be attributed to the improper storage of spawn, for good spawn may be ruined in a relatively short period by carelessness in that respect. Spawn should be kept in a place that will be both cool and dry. It will stand a low temperature without material injury. When properly stored, spawn will retain its vitality for at least one year. If much older, the dealer should disclose that fact to his customer. We guarantee all our spawn to be absolutely fresh and in prime condition when leaving our yards. We inspect every brick and ship none but the best.

2. Freight Rates. Brick spawn is rated as fourth class (Western classification) and third class (Official classification); in carload lots it is rated as fifth class in both jurisdictions. The rate St. Paul to Chicago is 25 cents LCL and 20 cents CL per 100 ths. St. Paul to Philadelphia and Philadelphia points, 73 cents LCL; to New York, 75 cents LCL; to Boston, 82 cents. Examine your freight bills.

3. Bricks, Boxes, Etc. Each brick of "Lambert's Pure Culture Spawn" measures 9 inches in length, $51 / 4$ inches in width, and is about $11 / 2$ inches thick. Our bricks peigh from $11 / 4$ to $1 \frac{1}{3}$ pounds and are packed in boxes containing about 160 bricks, more or less, and weighing about $225 \mathrm{tbs}$. including package. Each case is stenciled and distinctly numbered, and by reference to this number the original culture from which the spawn was produced can be traced in our records. We do not break packages or sell by weight.

4. Our Eastern Depot. Our eastern depot is located at Philadelphia. On shipments from that point an additional charge of one cent per brick is made to cover cost of transportation from St. Paul to Philadelphia at carload rates.

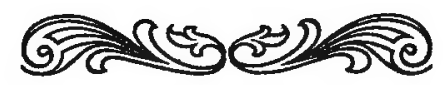

\section{American Spawn Company}

ST. PAUL, MINN.

Cable Address: "SPAWN, ST. PAUL." 


